\title{
,ane \\ Designing the Business Ecosystem of a Decentralised Energy Datahub
}

\author{
Sinan Küfeoğlu 1,*, Eray Açıkgöz ${ }^{2}$, Yunus Emre Taşc1 ${ }^{3}$, Taha Yasin Arslan ${ }^{4}$, Jan Priesmann ${ }^{5}$ (D) \\ and Aaron Praktiknjo ${ }^{5}$
}

Citation: Küfeoğlu, S.; Açıkgöz, E.; Taşc1, Y.E.; Arslan, T.Y.; Priesmann, J.; Praktiknjo, A. Designing the Business Ecosystem of a Decentralised Energy Datahub. Energies 2022, 15, 650 https://doi.org/10.3390/en15020650 Academic Editor: Ricardo J. Bessa

Received: 8 December 2021 Accepted: 12 January 2022 Published: 17 January 2022

Publisher's Note: MDPI stays neutral with regard to jurisdictional claims in published maps and institutional affiliations.

Copyright: (C) 2022 by the authors. Licensee MDPI, Basel, Switzerland. This article is an open access article distributed under the terms and conditions of the Creative Commons Attribution (CC BY) license (https:// creativecommons.org/licenses/by/ $4.0 /)$.
1 Department of Engineering, University of Cambridge, Cambridge CB2 1PZ, UK

2 Department of Computer Science, Norwegian University of Science and Technology, 7034 Trondheim, Norway; eraya@stud.ntnu.no

3 Department of Computer Engineering, Sabanci University, Istanbul 34956, Turkey; etasci@sabanciuniv.edu

4 Department of Computer Engineering, Istanbul Technical University, Istanbul 34467, Turkey; arslantah@itu.edu.tr

5 Chair for Energy System Economics, School of Business and Economics, RWTH Aachen University, 52056 Aachen, Germany; jan.priesmann@eonerc.rwth-aachen.de (J.P.); apraktiknjo@eonerc.rwth-aachen.de (A.P.)

* Correspondence: sk959@cam.ac.uk

\begin{abstract}
Datahubs step forth as convenient test beds for innovative solutions to create value from the energy data. There are numerous pilots and early trials for establishing energy Datahubs, especially in northern Europe. These are all centralised models, and the centralisation of data control and value creation can be regarded as contradictory to the decentralisation trend in the energy sector. This paper attempts to design the first decentralised energy Datahub ecosystem's business ecosystem, with the name DenHub, using Blockchain technology. This model enables easy access to transparent and flexible energy data and new business models that will emerge upon its use. All data produced, distributed, used, and curated will help researchers and entrepreneurs study this field and propose new business models to make the energy ecosystem more efficient, clean, and inclusive. The paper also presents the differences between centralised and decentralised methods by underlining the advantages and disadvantages of both approaches.
\end{abstract}

Keywords: Datahub; energy; data; blockchain; decentralised

\section{Introduction}

The rapid progress in technology development has caused many changes, impacts, and transformations in energy systems. From smart meters owned by end-users, over a decentralised generation of renewable electricity to smart grids that shape the entire network, many energy system components have managed to keep up with technology over the years. One of the most significant advantages of the devices and network structures is measuring and digitising production and consumption data. In this way, a balance of production and consumption has been achieved more effectively and predictably despite the increasing uncertainty in energy systems due to volatile renewable electricity generation. However, although this balance has many pillars, data sharing is generally only open to the institutions/companies or persons who have access rights or affiliations. Access to data is vital to achieving transparency, efficiency, competition, and unlocking new value through novel business models in today's energy market. At this point, Datahubs are attractive hosts to realise these goals and ideal testbeds to foster innovation and new businesses by enabling more accessible and efficient management of communication between market participants.

A Datahub is a data exchange platform that focuses on seamless and efficient data movement. It might not be regarded as a technology as it is a method for determining 
where, when, and for whom data must be mediated, exchanged, and then linked and/or persisted more efficiently [1]. The Datahub acts as a bridge to store and distribute the produced data. As highlighted by [1], "A DataHub enables data sharing by connecting data producers with consumers of data. Endpoints interact with the DataHub by providing data into it or receiving data from it, and the hub provides a mediation and management point, making visible how data flows across the enterprise".

An Energy Datahub is the name given to the Datahubs where the data generated by the services and consumption information provided by the market players are collected. As reported by [1]: “... Energy DataHub, centralised back-end repository of historical and current energy data. It streamlines energy data flows across the sector, and enables consumers, authorised agents on consumer's behalf, and other users to access energy data" [2] There are a lot of advantages and reasons for using an energy Datahub for data collection and sharing. These include increasing market transparency and competition, presenting customer-specific tariffs, boosting Demand Response and enabling novel business models. As stated by [3], to propose energy Datahubs as sound business cases, Demand Response schemes, smart grids and Internet of Things (IoT) compatible devices and infrastructure, smart tariffs, and on-site small-scale renewable generation are needed.

An Energy Datahub will enhance all stakeholders' efficiency in the power supply chain, including customers, suppliers, and transmission companies [3]. Energy data sharing strives to unlock value from data inside the energy system, promote innovation in new goods, services, and companies, and create more efficient, cost-effective systems that benefit customers and realise the advantages of clean energy [4]. Greater data visibility, infrastructure and asset visibility, operational optimisation, open markets, and nimble regulation will be required to achieve a modern, digitised energy system [4]. According to a recent energy Datahub study by [3]: "one of the trends in the energy sector is about transparency and market competition. A Datahub enables easier and more efficient management of communication between market participants. The equal access principle provides an equal market condition for all electricity suppliers with standard regulations for enrolment and distribution of market data. In addition to transparency and democratisation of energy systems, Datahubs will be key players for achieving flexibility in power systems" [3]. A common system will also create new applications for electricity customers, such as apps that will enable users to save energy or monitor their usage [5].

State-of-the-art Datahub implementations are all centralised models. The centralisation of data control and value creation can be regarded as contradictory to the decentralisation trend in the energy sector. We, therefore, propose to challenge the current approach of centralised Datahubs and use the technological capabilities already available in the energy system today to design a decentralised solution.

This paper aims to design the business model ecosystem of a decentralised energy Datahub: DenHub. The DenHub can foster transparency, democratisation, and flexibility in data flow in the electricity markets. The decentralisation of Datahubs is also part of our design as a safer and faster method by eliminating the risk of a single point of failure. In this context, we aim for a model in which all actors in energy systems can manage the system together, and the data will not be changed by using hybrid blockchain techniques. As a first step, a literature review will be performed on smart meters with the Internet of Technologies, enabling technologies. The capability of smart meters is an essential key point for the realisation of the study. Then, the integrability of the multi-participant blockchain network structure will be investigated. The consensus structure of decisionmaking and validation mechanisms in such a structure will be detailed at this stage. Finally, the regulatory points regarding data protection and data security will be examined, and a proposition will be created on how to eliminate intermediaries in the energy data system. This research aims to explore the advantages of a democratic data-sharing network, which will provide certain benefits to customers and end-users. 


\section{Materials and Models}

Boosting the amount of energy data brought attention to Datahubs as platforms where value can be created and distributed among stakeholders. Energy data can be collected from power systems, Electric Vehicles, and buildings. The number of Internet of Things connection points is estimated to reach 83 billion worldwide by 2024 [6]. However, again according to estimations, about only $10 \%$ of this vast amount of data collected from these sources are analysed and put to use [6].

Data is vital to run daily operations efficiently and propose novel market strategies. However, what kind of data could and should be collected, stored and processed is another matter. Reaching reliable, continuous, and real-time data is. There are numerous applications of usage data in the energy market. Multiple energy-related data analytics aspects can be summarised as [7-9]:

- Wholesale and retail electricity prices

- Faster, easier, more efficient and more customer-friendly billing

- Consumption metering per $15 \mathrm{~min}$ via Automated Meter Reading (AMR)

- Power outage assessment and early warning mechanisms

- Fast detection and locating the anomalies in the power system

- Real-time pricing or other smart tariff services

- Demand Response (DR) measures to save energy

- Efficiency in energy generation

- Algorithmic trading

- Automated trading

On the other hand, Demand Response and power system flexibility introduces certain benefits and savings for the network planners, Distribution System Operators (DSOs), Transmission System Operators (TSOs), retailers, and consumers. Power system flexibility can be explained as the grid's ability to respond to sudden changes in supply and demand in the power system. There are various techniques to realise power system flexibility. Some of them are investigated in detail in [10-13]. AMRs and consumer/prosumer involvement will foster flexibility in the service and residential sectors [14]. As suggested in the studies [11,15], smart homes will be a crucial feature of future energy systems because of the potential benefits of supporting flexibility in the residential sector.

Various energy Datahub pilots and early market players exit, especially in northern Europe. The Datahub survey by ebIX compiles useful technical, organisational, security, and financing information about these Datahubs [16]. In addition to the ebIX report, we reviewed the company websites and prepared Table 1 to summarise the crucial information regarding the existing Datahubs in Europe.

Table 1. Energy Datahubs review.

\begin{tabular}{ccccc}
\hline Company & Country & Datahub Owner & $\begin{array}{c}\text { Datahub Usage } \\
\text { Situation in State }\end{array}$ & Finance/Revenue Stream \\
\hline ATRIAS & Belgium & DSO & The construction phase & Not applicable yet \\
\hline ElHub & Norway & Statnett, Norway's TSO & In service & No information available \\
$\begin{array}{c}\text { DCC (Data } \\
\text { communication } \\
\text { company) }\end{array}$ & UK & $\begin{array}{c}\text { Capita PLC is a private } \\
\text { company and regulated by } \\
\text { the Office of Gas and } \\
\text { Electricity Markets } \\
\text { (Ofgem) }\end{array}$ & In service & $\begin{array}{c}\text { Costs are recovered from energy } \\
\text { suppliers, network operators, } \\
\text { and other authorised users. }\end{array}$ \\
\hline $\begin{array}{c}\text { Energie Data } \\
\text { Services Nederland } \\
\text { (EDSN) }\end{array}$ & Netherlands & DSO and TSO & In service & $\begin{array}{c}\text { Depending on the specific } \\
\text { function, the Datahub is } \\
\text { financed by the grid. }\end{array}$ \\
\hline Energinet.dk & Denmark & Energinet, Denmark's TSO & In service & No information available \\
\hline
\end{tabular}


Table 1. Cont.

\begin{tabular}{ccccc}
\hline Company & Country & Datahub Owner & $\begin{array}{c}\text { Datahub Usage } \\
\text { Situation in State }\end{array}$ & Finance/Revenue Stream \\
\hline Elmarknadshubb & Sweden & $\begin{array}{c}\text { Svenska Kraftnät, } \\
\text { Sweden's TSO }\end{array}$ & $\begin{array}{c}\text { Project on hold due to } \\
\text { delays in legislation } \\
\text { and other uncertainties }\end{array}$ & $\begin{array}{c}\text { All stakeholders will be billed by } \\
\text { the hub owner (TSO). The cost } \\
\text { for the Datahub will not be } \\
\text { financed by the grid fee. }\end{array}$ \\
\hline $\begin{array}{c}\text { Fingrid Datahub } \\
\text { Oy }\end{array}$ & Finland & Fingrid Oyj, Finland's TSO & In service & $\begin{array}{c}\text { Costs will be charged to users. } \\
\text { The exact charging scheme is not } \\
\text { available yet. }\end{array}$ \\
\hline Elering & Estonia & Elering, Estonia's TSO & In service & No information available \\
\hline
\end{tabular}

According to [3], "Energy DataHub primarily serves market players in the electricity market, who use Energy DataHub to communicate with each other about the electricity consumption of consumers and to make sure that they have all the information necessary to bill their customers. Natural key participants of the Energy DataHub will be Distribution System Operators (DSOs), Energy Exchange, Energy Market Regulatory Authority, Transmission System Operator (TSO), and retailers" [3]. Figure 1 shows which participants are involved with access types in the DenHub ecosystem. There are two access types which are premium and basic accesses. In the premium access, the data on the Blockchain will be shown entirely and exclusively to who is requesting; on the other hand, nodes with basic access will only be able to see some of the data, such as the data they generate and send to the network. Some market players play a role in these networks as operator nodes. These nodes form the consensus on decision changes in the network and are also the network's validators. The rest of the nodes represent member nodes that do not have permission in changing the network operations.
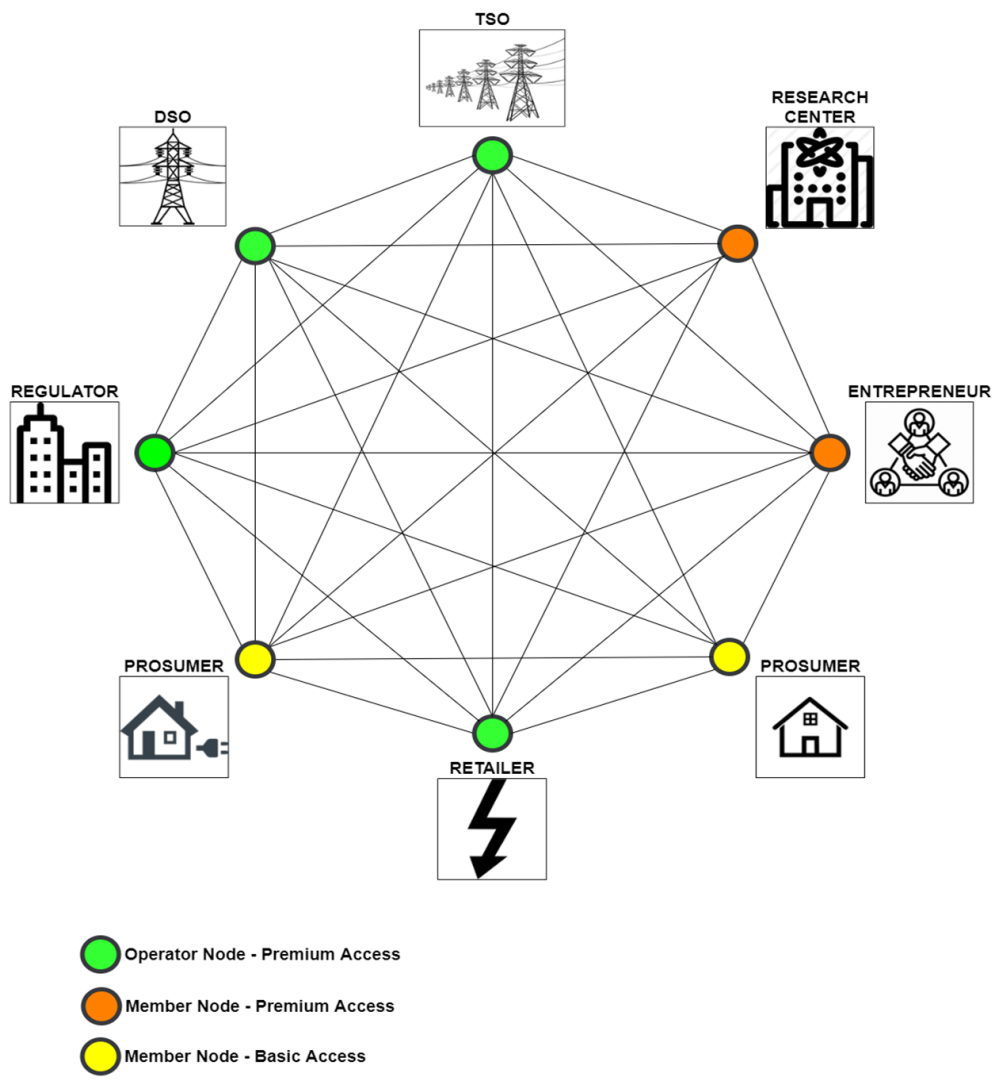

Figure 1. Blockchain-based Energy Datahub (DenHub) Ecosystem Participants. 
Datahubs can be found structurally in two different ways. The first is centralised Datahubs, where data is collected in a single centre and distributed from there. The second option is decentralised Datahubs, which are distributed systems and not centralised. Figure 2 shows the ecosystem of a centralised energy Datahub. The benefits, risks, and structure of these two structures are compared in Table 2 below.

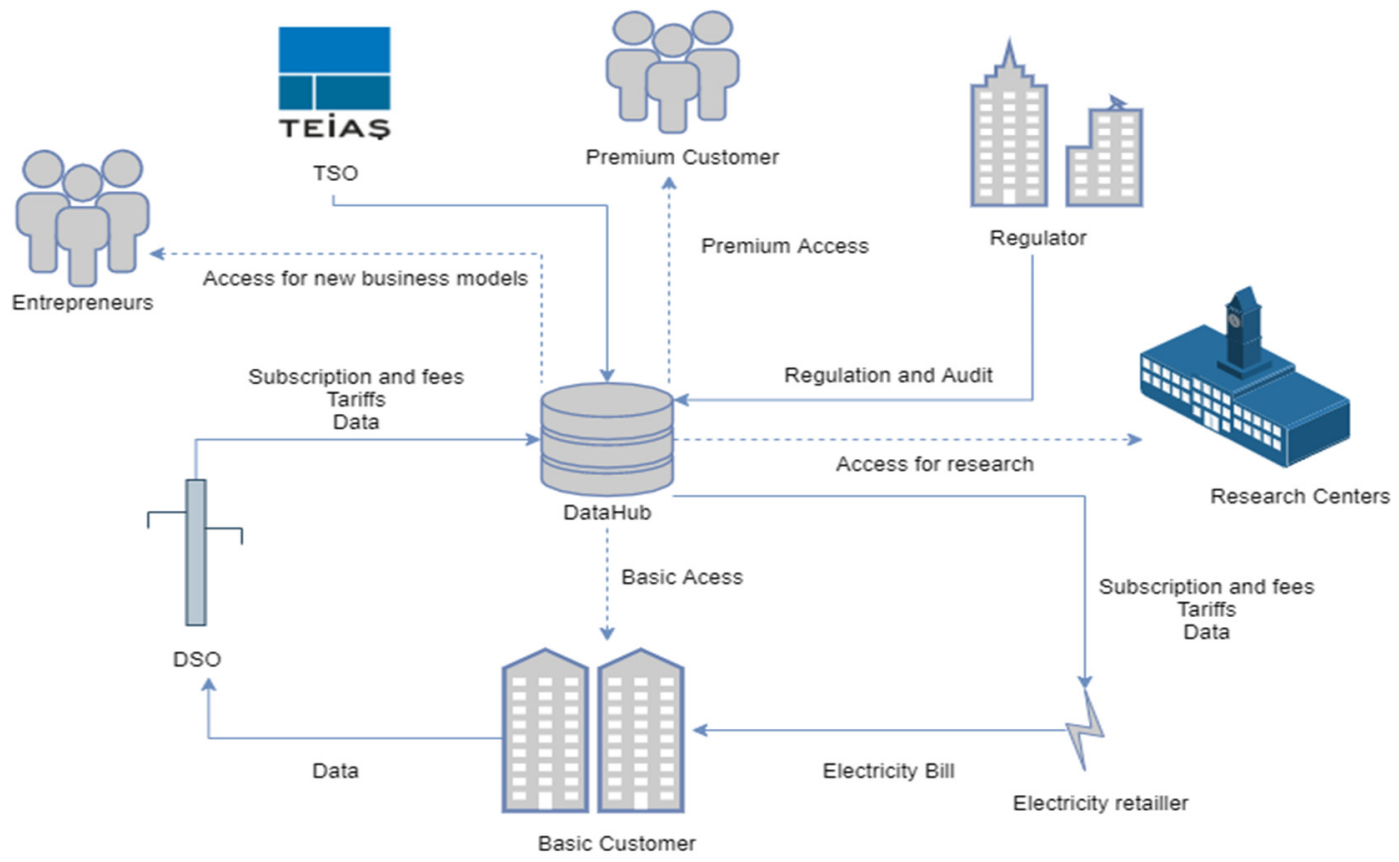

Figure 2. Centralised Energy Datahub Ecosystem Participants [3].

Table 2. Centralised vs. Decentralized Datahub Comparison.

\begin{tabular}{|c|c|c|}
\hline & Centralised Datahubs & Decentralised Datahubs \\
\hline Ownership/Accountability & $\begin{array}{l}\text { The owner of the Datahub is the } \\
\text { centralised authority; there is no } \\
\text { institution for checking accountability }\end{array}$ & $\begin{array}{c}\text { The owner of the Datahub is the network itself, and it is } \\
\text { open for all the market players, including basic } \\
\text { customers }\end{array}$ \\
\hline Management & Easy to communicate and coordinate & $\begin{array}{l}\text { Can be managed by a well-constructed consensus of the } \\
\text { market players }\end{array}$ \\
\hline Updates/Changes & Top-down approach & Collective approach \\
\hline Process Maintenance & Easy to maintain & Small changes generally are ignored \\
\hline Security & $\begin{array}{l}\text { Hard to protect; records will be held only } \\
\text { in centres, and back-ups are held in } \\
\text { external centres. }\end{array}$ & $\begin{array}{l}\text { Easy to protect; records will be held for all of the } \\
\text { network participants }\end{array}$ \\
\hline \multirow[t]{2}{*}{ Privacy/Access } & \multicolumn{2}{|c|}{$\begin{array}{c}\text { Premium customers, including DSOs, TSOs, regulating authorities, exchanges, and retailers with } \\
\text { premium access }\end{array}$} \\
\hline & \multicolumn{2}{|c|}{ Basic customers with basic access } \\
\hline Risk Assessment & Single point of failure & $\begin{array}{l}\text { No single point of failure, storing data across all } \\
\text { network of computer }\end{array}$ \\
\hline Scalability & $\begin{array}{l}\text { Easy to distribute data to users from a } \\
\text { single-centre, high }\end{array}$ & $\begin{array}{l}\text { A bottleneck for current decentralised systems, } \\
\text { especially with large numbers of users, but can be } \\
\text { handled with several techniques (sharding, block size, } \\
\text { DAGs). }\end{array}$ \\
\hline Regulation & $\begin{array}{l}\text { Large number of third parties mean more } \\
\text { regulation and complexity }\end{array}$ & $\begin{array}{c}\text { Designed to be more compatible with regulations, few } \\
\text { third parties, transparent participant and smart contract } \\
\text { structure }\end{array}$ \\
\hline
\end{tabular}




\subsection{The Business Ecosystem of the DenHub}

The Boston Consulting Group summarises the business ecosystem design in six steps as follows [17].

\subsubsection{The Problem You Want to Solve}

A. The size of the problem

Ongoing fast-paced developments in technology have surrounded all aspects of our lives, from finance to domestic appliances. Leading technologies such as the Internet of Things (IoT), Blockchain, or 5G are expected to make these technologies more efficient, userfriendly, transparent, and trustless. We (as a society) feel the changes of these characteristics of developing technologies in our daily lives. However, renovations on energy systems cannot keep up with the fast-paced developments due to heavy regulatory burdens [18]. Energy markets can be more efficient, more transparent, and trustless with the suitable implementations on energy systems. One of the biggest problems with the de facto energy market ecosystem is that it does not alleviate value creation from energy data in its current structure despite its vast potential. Energy DataHub ecosystems are one of the most significant developments (mainly applied part in Northern Europe) where economic and systematic efficiency problems are handled considerably.

Notwithstanding, there are several significant drawbacks of the current design of the Energy Datahub ecosystems. They are not prone to the single point of failure out of the starting gate because they are centralised and not agile as a current technological system should be. They provide a very closed ecosystem with centralised data management on energy data. That being the case, transparency over the ecosystem heavily relies on regulations and inspections over the players. The regulatory arrangements intrinsically create barriers for a flexible ecosystem. Also, actors' rights over the ecosystem and value creation process can be handled more democratically, with freer allocation. The liberation of individuals is another concern discussed in the energy market. The current system's capacity to include the end-user into the market is limited even with a relatively innovative solution like Energy Datahubs. The liberated individuals amongst the market should have more rights over the data they produce. It is possible to follow the energy trends like digitalisation, democratisation, decentralisation, deregulation, and decarbonisation. To some degree, it is required to build a better solution for our world's future on the energy systems.

B. An ecosystem as a right choice

Boston Consulting Group defines a business ecosystem as "a dynamic group of largely independent economic players that create products or services that together constitute a coherent solution" [17]. As well as independent players, bringing a solution to an existing and awaiting problem has its particular importance. Energy markets around the world have been a closed ecosystem. All the players and their roles have been predetermined, and it is hard to enter the energy ecosystem. While this has been changing on the energy supply side with the large-scale adaption of decentral renewable energy generation, this problem remains unsolved mainly on the demand side [18]. The strict market rules and lack of incentives for entrepreneurs and third parties slow down the innovative collective movements in the energy markets. The current energy ecosystem is old and needs to be somehow revolutionised to be more efficient, eco-friendly, and more open to the public or hybrid entrance. We are one step closer to the solution thanks to the latest improvements being implemented, such as Smart Metering Infrastructures and Energy Datahubs.

C. The ecosystem you need

Energy markets and systems are already forming a business ecosystem. Energy markets need a renovated ecosystem compatible with the energy trends: digitalisation, democratisation, deregulation, decarbonisation, and decentralisation. As previously stated, this type of ecosystem is required to make the right decision. 
Our approach heavily depends on decentralisation. An elaborated decentralised Energy Datahub ecosystem can solve the problems above of the energy sector following the evolving energy trends.

\subsubsection{Stakeholders and Participants of the Ecosystem}

A. What are the players and their roles?

On top of the main roles of the players in the energy market, such as distributing electricity or regulating the market, roles for the players in the Datahub ecosystems are different, which are read and write accesses. Centralised Datahub Ecosystem consists of nine different players with different roles. Entities have different access rights to the centralised database.

The players are [3]:

- $\quad$ Transmission System Operators (TSOs)-Full Access (Read and Write)

- Distribution System Operators (DSOs)-Read-Only Access

- Premium Customers-Read-Only Access

- Basic Customers-Profile Access

- Regulators-Read-Only Access

- Electricity Retailers-Read-Only Access

- $\quad$ Research Centers-Read-Only Access

- Entrepreneurs-Read-Only Access

- The Datahub-Full Access (including commit access)

One of the most important value propositions of a Decentralised Datahub is eliminating intermediaries or repositioning intermediaries in response to inefficiency, industry requirements, and trends. Accordingly, The Datahub entity is being eliminated from the process since the read, write, and data storage process will be handled in a decentralised manner. Also, depending on the choice of implementation (public or private Blockchain) read, write and commit access rights of the other player may vary.

B. Who should be the orchestrator?

Boston Consulting Group emphasises four main characteristics of a successful orchestrator in a business ecosystem [17]:

"A successful orchestrator:

Must be accepted as an essential part of the ecosystem by the other players inside the ecosystem.

Should have a central role without any dependencies to other players to enable coordination

Should be perceived as fair/neutral, not a competitive threat by other players

Should have a high capability to bear large upfront investments".

A 'strong' central orchestrator with authority is used in the traditional approach. While in decentralised systems that are built on a blockchain, we spread the control and coordination among participants.

The first three characteristics of a successful orchestrator inherently describe blockchain infrastructure. Not being much different from most of the emerging business ecosystems, a software platform being the orchestrator, in the DenHub model, a blockchain architecture will mostly handle the orchestrator role with a decentralised approach, providing more neutral structure to the players and having limited dependencies to any other players in the ecosystem. However, full decentralisation will not be feasible at this stage. That is why we have built our solution with two layers where the consortium will be built with the trusted institutions (TSO, DSO, Retailers, and Regulator), which constitutes Layer 2. In Layer 1 basic customers, premium customers, entrepreneurs, and research centres will take their places with different permissions and roles on the system.

Also, it will be the essential part without a doubt. The government should shoulder the fourth characteristic of the orchestrator at the initial stage by providing incentives and reliance to the players in a disruptive environment mostly governed by a decentralised 
system that can be seen as risky. Thus, vastly researched and discussed, complicated and costly process of full decentralisation on the energy systems can take its first step with the decentralised Energy Datahub (DenHub), which only depends on the multidimensional data exchange and not multidimensional energy exchange directly results in eliminating the infrastructure cost for the energy transmission.

Blockchain plays a vital role in exactly where it develops in response to this question. This question was answered on the central orchestrator's axis in the traditional energy sector, and certain results were achieved. On the other hand, industry trends are transforming the existing system of orchestrators. In response to inefficiency, demands of the industry, and developments, certain results, DenHub's use-case of Blockchain reposition intermediaries and orchestrators in the right direction.

C. How can the orchestrator motivate the other players?

The DenHub System will not be feasible without the regulator's coordination with the ecosystem. The major entities in the Datahub Ecosystem like TSOs, DSOs, and electricity retailers will not be having significant monetary incentives due to their monopolistic natures on the centralised Datahub ecosystem and conventional energy market. The regulator's role here is vital for the DenHub to be viable, considering those entities play a crucial role in the ecosystem. The only way to motivate those entities is through regulatory arrangements.

Besides TSOs, DSOs, and electricity retailers, the orchestrator's decentralised nature will motivate other players in the ecosystem. Decentralisation comes with democratisation. Even though the degree of democratisation depends on the architecture of the Blockchain, any of the blockchain implementations will bring more democratisation than it is in the current implementations. That being the case, distributing data control over the ecosystem eliminates the risk of monopolisation, which comes up as a severe problem for the Central Datahub Ecosystems. Moreover, basic customers, premium consumers, and entrepreneurs will have more direct access to the ecosystem. For example, basic consumers will have the right to their energy-related data, possibly creating a new market, and new business opportunities will emerge in that market for entrepreneurs. The required investment amount for the participation of those entities will be limited, considering the decentralisation will build upon software that the government can fund. Also, on centralised Datahub ecosystems, end-users only have read access over their usage data, and entrepreneurs who can build new business opportunities over that data need to contact the Datahub entity where all the individual data are aggregated. This central data management left end-users without control of their own data. Another aspect of end-user participation is decentralised storage. Since the data won't be collected in a single database, end-users can use their unused storage in their personal computers to serve the ecosystem in return for the monetised incentives in an ideal and seamless ecosystem mechanism.

\subsubsection{The Initial Governance Model of the Ecosystem}

\section{A. How open should the ecosystem be?}

The governance model of the centralised Datahub ecosystem has already paved the way for decentralisation by raising the importance of data in the energy sector. However, it is a fairly closed and restrictive ecosystem design. Directly and highly regulated and the number of players in the ecosystem is rather low, considering the size of the ecosystem. The ecosystem design of the DenHub Model should be addressed to this problem and the problems mentioned above in accordance with the energy trends, which are decentralisation, democratisation, deregulation, and decarbonisation through involved end-users. Especially these four trends affect the main aspect of the ecosystem design, which in fact directly points to the openness degree of the ecosystem. In DenHub, one of our goals is for endpoint users to involve more in the value creation process. That requires a more open ecosystem design with freer market design and less regulation. "The balance between rules of value creation and value sharing should reach the equilibrium in the long-term due to freer market properties." The degree of openness should be severely enhanced compared 
to the centralised Energy Datahub ecosystem. Again, thanks to the decentralised nature of our design, less regulation will be needed since the transparency over the system will be handled by the Blockchain. However, the initial governance model should be regulated and supported semi-open ecosystem.

Every player on the centralised Datahub ecosystem will have more participation in such a semi-open ecosystem. End-users especially will have the ability to monetise their data over the Blockchain, even build their own business by providing data storage to the ecosystem. The semi-open property of our DenHub Model needs to be fulfilled since every individual player needs to be recognised by the regulatory power. In other words, the hybrid-blockchain system that involves governmental and regulatory issues need to Know Your Customer (KYC) protocols. That is why our approach is a Hybrid Permissioned blockchain for the ecosystem. In addition to this, Hybrid Permissioned Blockchain also helps solve one of the most complicated tasks in permissionless public blockchains: scalability.

\section{B. What should the orchestrator control?}

When describing the orchestrator at the control level, a distinct parenthesis may be necessary for the governments or regulators. Because we can also consider the system auditability while talking about control in this area. The government as the orchestrator has one most important issue to deal with: the regulation for the monopolistic players. Also, KYC issues for the end-users and entrepreneurs should be handled by the government.

Control at the business model level is supplied by the consensus of the Blockchain participants and the protocols determining those rules. The distributed ledger technology (DLT) enables the participants to monitor the system at a particular level and decide on the system's future. The crucial element here is that the decision is not taken by a strong orchestrator but by force produced by protocols of unity among the participants.

\subsubsection{Capturing the Value of the Ecosystem}

A. What and whom should you charge?

The Centralised Datahub ecosystem charges premium customers, entrepreneurs, and research centres, who want to reach all collected datasets [3]. According to the International Energy Agency's estimation, only around 10\% of the energy data is being collected and used [6]. Data producers (anyone who uses and/or produces energy) will naturally wish to monetise their own data. Just like in the centralised model, data is the value. Instead of a centralised entity taking almost all the advantage of the produced data from energy usage, the DenHub model distributes the value-creating and sharing process over all the players in the ecosystem. Especially the relatively small players in the ecosystem. Another aspect of value creation is data storage. Data storage issues will also be handled in a decentralised manner. Basic customers can share their unused storage in their personal computers for the system, or new business opportunities can emerge for entrepreneurs by serving the system with different storage solutions where the higher competition of the free market enables more efficient outcomes as long as the risk of monopolisation is being regulated by the orchestrator (in that case it can be either the government or the software who regulates the monopolisation). Anyone with the right customer access to the data can buy the vast data directly from the data producers (energy users). Layer 2 players who form the consensus mechanism should be rewarded by the system for their work for keeping the data records safe on the Blockchain. The reward and specific monetisation strategies on blockchain and storage mechanisms can be changed depending on the final implementation and final system designs.

\subsubsection{Solving the Chicken-Egg Problem}

A. What does it take to achieve critical mass?

The DenHub model's ultimate goal is to replace the current centralised Datahub ecosystem with the decentralised one. The orchestrator's role here is more than critical. The 
critical mass will not be achievable without government support and necessary regulations. To accomplish mass adoption in the DenHub ecosystem, it is vital to convincine regulative authorities. Incentive mechanisms for convincing the regulatory power are explained above. Mainly, energy trends and less regulative necessities would be convincing the governments.

B. What is the minimum viable ecosystem?

The government, as the orchestrator, can select the pilot areas for the system. The pilot area needs a place that consists of all players in the ecosystem, such as a city or a district where there is at least one of each Layer 2 player and enough households, such as an industrial zone close to the residential district.

C. Which side of the market should you focus on?

Since Layer 2 players are incentivised by the regulations and the monetary benefits of being the premium nodes where they form the consensus mechanism, Layer 1 players should be the part that is being focused on. Economic and social benefits of the Layer 1 players are sizably increased compared to the centralised architecture. It is important to acknowledge everyone on Layer 1 about the enhancements on their behalf in the DenHub Model. Additionally, there will be numerous business opportunities for the entrepreneurs with decentralisation.

\subsubsection{Ensuring the Evolvability of Your Ecosystem}

A. How can you scale/defend the ecosystem?

In our case, the initial supply-side scalability of the ecosystem highly depends on the orchestrator support and the collaboration of the Layer 2 players. So, the ecosystem must ensure that the orchestrator and the Layer 2 players work in cooperation. Also, the expansion of the ecosystem should be gradual. It is impossible to change all the infrastructure at once, so the demand-side of the economy should string along with the gradual changes in the ecosystem. Involving all the users in the energy sector, which contains every household, user from every age interval, so when the ease of use for the older generations became stable, with better interfaces, easier automated data selling and buying (also business opportunities for entrepreneurs) then the ecosystem becomes fully grown. Until that time, the ecosystem's focus should be on the younger generations with more adaptability to a complex new technology that the ecosystem can grow securely step-by-step.

B. How can you expand the ecosystem?

A model was developed to bring the ecosystem as a whole and the energy and data communities together. Different communities will arise as a result of the gathering of participants. These communities will help each other meet their energy and data needs by cooperating. At the same time, participants will have the opportunity to profit from the monetisation of certain values.

A significant influence in the expansion of the ecosystem will be played by the incentive mechanisms that have been built for each participant in the system. Through our ecosystem, communities with internal governance processes will be able to bring together non-system elements that might otherwise be incompatible.

\section{Protecting against backlash}

The participants were provided with an environmentally friendly, low-carbon credit, a low-energy system that was designed using the suitable methodology and designation of consensus. Some of the proof experiments conducted by the participants may result in excessive energy consumption in Blockchain systems. However, many people's opinions of blockchain technology continue to be dominated by Bitcoin [19]. Additionally, it is widely accepted that Bitcoin uses a tremendous amount of energy. Furthermore, it is well-known that Bitcoin uses significant energy throughout its proof operations [20]. In Section 3.1, we 
show how the problem of energy required per blockchain transaction is gradually solved by developing new consensus algorithms.

In certain applications, blockchain technology can be considered to be in its early stages. However, aside from technological advancements, the business sector develops at a breakneck pace. The business level of immaturity is being passed swiftly. Advancements follow these advancements in the commercial area in the technological section. Even though they are viewed as a complex technology in the background, they can become even more useful than the commonly used tools of today through the implementation of new UI/UX solutions. Because of the user-friendly front-end, operations may be performed quickly and efficiently without the need for participants to be aware of what is going on in the background.

\subsection{The Enabling Technology: Smart Metering}

\subsubsection{Smart Metering}

Smart metering (also called Advanced Metering Infrastructure, AMI) is the new type of digital energy metering system to replace conventional energy metering. Smart metering enables bi-directional and instantaneous data exchange between the customers and suppliers in energy markets (mostly in electric, also in water and gas) [21]. The data exchange between customers and suppliers is meant to organise energy supply and demand accordingly and more efficiently. On the customer side, smart metering provides several services such as accurate data measurement, up-to-date billing information, accessibility of one's own data, which can help to make more informed decisions towards their energy usage etc. [22]. On the supplier side, data received and collected from smart meters is being collected on a central hub, which allows suppliers to obtain and adjust energy demand at different levels. It was stated that the most important market drivers in Europe for deploying smart meters are the digitalisation of distribution grids, optimising network operations, and dynamic tariffs for households [22].

\subsubsection{Smart Metering Adaption}

As of $2020,42 \%$ of meters in the UK are either smart meters in smart mode or smart meters in the traditional mode, with a total number of 23.6 million smart meters installed [23].

In the USA, 83,539,594 residents have smart meters installed until 2019. The total number of households in the United States was 128.58 million in 2019 [24]. In 2019 estimated $65 \%$ of households had smart meters installed. The total number of smart meters installed over different sectors, which are commercial, industrial, and transportation sectors, is $94,838,855$ [25]. Furthermore, smart meters are deployed over European countries such as Denmark, France, Norway, Sweden, Finland, and Spain [26]. Widespread smart metering infrastructure installations over various countries and advanced abilities of these smart meters encourage one to handle their own data and possibly open the way for decentralising information on energy markets. Reservations against installing a smart meter are correlated with security in the preservation of personal data, [27] showed for the German case.

In conclusion, the idea of broader and larger adoption of the smart meter technology act as an enabler for Datahub platforms and enable market players to actively participate in and benefit from data sharing.

\subsubsection{Working Principles of Smart Metering}

At the very basic level, smart meters replace traditional metering infrastructures to enable bi-directional information and energy flow. Smart meters measure the usage of the related energy that they are built to measure. Then they send the information to the energy supplier at predetermined intervals. Also, suppliers can send related information on usage to the consumer. This information flow enables smart tariffs, optimisation of the network, detection of faults in the systems, etc. How the data is transmitted and which data is transmitted through AMI are the key concepts for this enabling technology to be a part of a decentralised Datahub possibly. 
Smart metering systems are basically structured upon four main parts, which are the following [28]:

A. The smart metering device

An interactional user-end device keeps track of the energy consumption data and enables users to be informed about their data, billing tariffs etc. Two main purposes of smart meter devices are to transmit the data for accurate billing and keep the user informed through user interfaces. Advanced Smart Meters can also communicate with other residential IoT devices through Home Area Network.

\section{B. The data concentrator}

The main function of the data concentrator is self-explanatory. Data concentrators are collecting and gathering data from the smart meters and work as a "master node in a communication network" [28]. Concentrators communicate with the household smart meters and power plants through the Neighborhood Area Network. Then they redirect the concentrated data to the central management system through Wide Area Network (WAN). They are primarily placed in Power Transformers.

\section{A communication system that enables bi-directional data flow}

Without a doubt, the communication infrastructure has critical importance for smart metering systems. Also, the chosen technology for the infrastructure is going to be the enabler for a decentralised Datahub. Smart meters transmit the usage data through several different networks. The general implementation consists of three different layers of networks, which are Home Area Network (HAN), Neighborhood Area Network (NAN), and Wide Area Network (WAN). Depending on the implementation of smart metering infrastructure, different communication infrastructures can be implemented at those three layers. These networks can be both wireless and through power lines. Since implementing the advanced metering infrastructures, proprietary mesh networks have been the most used ones amongst the variety of communication networks that can be useful for the DenHub Model [28]. Also, there is no 'one fits all' solution for smart metering communication networks. Therefore, there is no unification over the choice of network infrastructure [29]. Standardisation of these parts could ease the decentralisation process. These are going to be reviewed to find a suitable one for a decentralised Datahub, the DenHub, model.

\section{Central management and control systems}

Central Management (Control Centers) systems are places where the gathered data from smart metering systems are being analysed and used for good such as informative, smart billing tariffs, or layer two solutions being produced for the end-user. The main problem of these Control Centres is that they are not prone to single-point-of-failure. The DenHub Model basically aims to decentralise data management to achieve a more transparent, trustless, and secure process.

Figure 3 shows how the data exchange takes place between different entities under the smart metering network.

Smart meters interact with the residential IoT devices such as in-home displays and send information about household energy consumption through Home Area Network (HAN). Data collected from smart meters in the households within the neighbourhood or a specified area, gathered and concentrated in the Data Concentrators, which act like "master nodes" in the infrastructure. Data concentrators enable bi-directional information flow between themselves and smart meters and in some conditions between themselves and the power plants. Data collected and concentrated in the Data concentrators then sent to the Central Control Systems (Datahub) to be analysed. The useful information will be distributed as smart billing tariffs etc., through Advanced Metering Infrastructure or Wide Area Network depending on the network choice. 


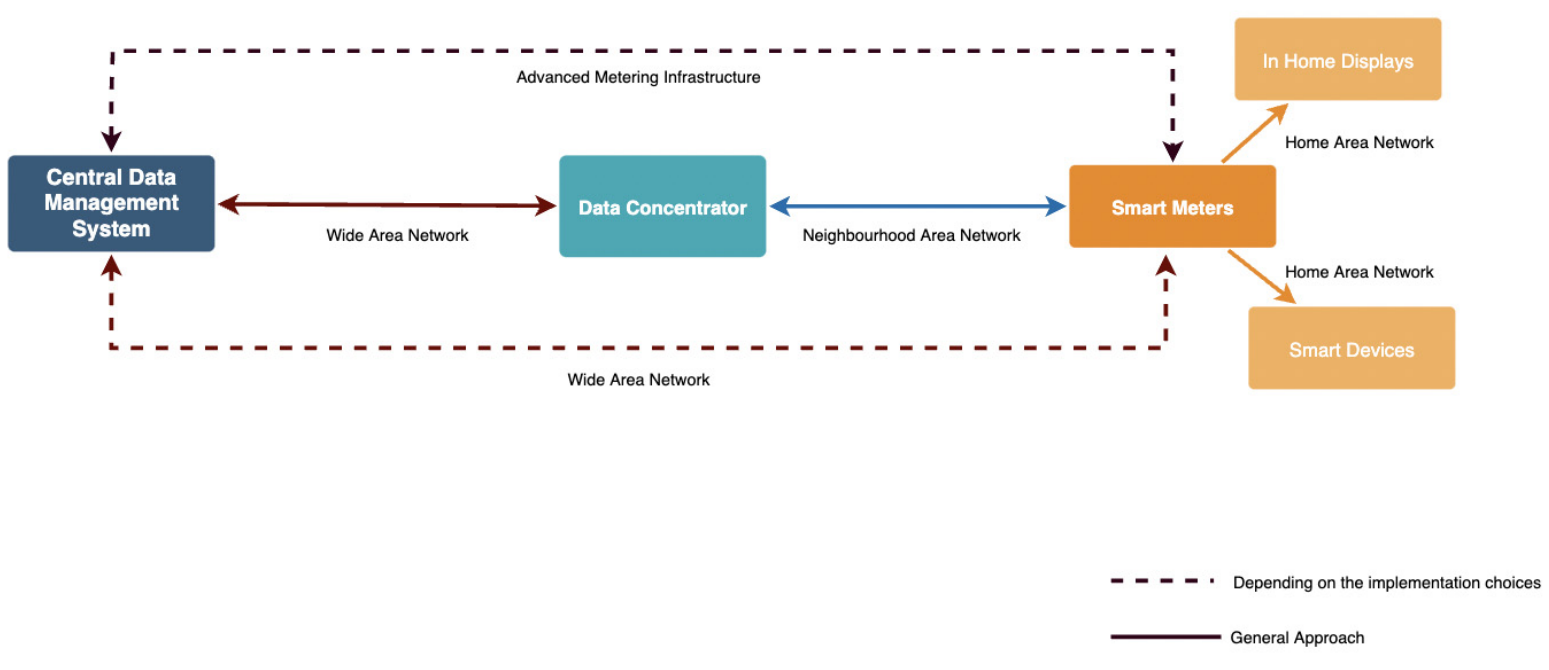

Figure 3. Data Flow Chart on Smart Metering Infrastructure.

\section{Methods}

Blockchain is a distributed chronological ledger that can record, validate and store transactions on a peer-to-peer network. Networks can self-organise, scale, and operate with the strength of peer-to-peer architecture, even in the face of computer/network failures and a remarkably diverse population of nodes, without the need for a central server and its expense [30]. This is achieved using cryptography and consensus algorithms. Different blockchain models exist, such as the Bitcoin or Ethereum models, that were initially created for a certain purpose, as shown in Table 3.

Table 3. Comparison between Bitcoin and Ethereum.

\begin{tabular}{ccc}
\hline & Bitcoin & Ethereum \\
\hline Release date & January 2009 & June 2015 \\
\hline Usage & To buy goods and services, to store value & To create distributed applications \\
\hline Purpose & $\begin{array}{c}\text { Cryptocurrency created to compete } \\
\text { against the gold standard and fiat } \\
\text { currencies }\end{array}$ & $\begin{array}{c}\text { Token able to facilitate smart } \\
\text { contracts (e.g., in an energy } \\
\text { exchange) }\end{array}$ \\
\hline
\end{tabular}

Decentralisation and digitisation of energy networks provide up new commercial and technology options and futures. As the study [31] suggests, decentralised energy projects are more inventive, interoperable, borderless, and transparent as a result of blockchain technology. The Blockchain has the potential to eliminate transaction vulnerability, insecurity, and ambiguity by giving full transactional disclosure and generating a single truth for all network participants.

\subsection{Incentives Structure}

An incentive is any design element that influences the behaviour of system participants by altering the relative costs and benefits of the options available to them. Incentives include pay-for-performance reward systems that earn participants valuable things like money, data, or tokens. For example, In Bitcoin, the finder of the block is rewarded for their efforts with newly created coins (so-called mining). The reward provides an incentive to add blocks to this type of network [32].

Blockchain platforms provide an infrastructure for incentives. Incentive design is a critical part of effective blockchain platforms' overall consensus and economic design. It is inevitable to consider the incentive mechanism in multi-participant systems such as the DenHub. Figure 4 represents the places of the incentive mechanisms for DenHub. 


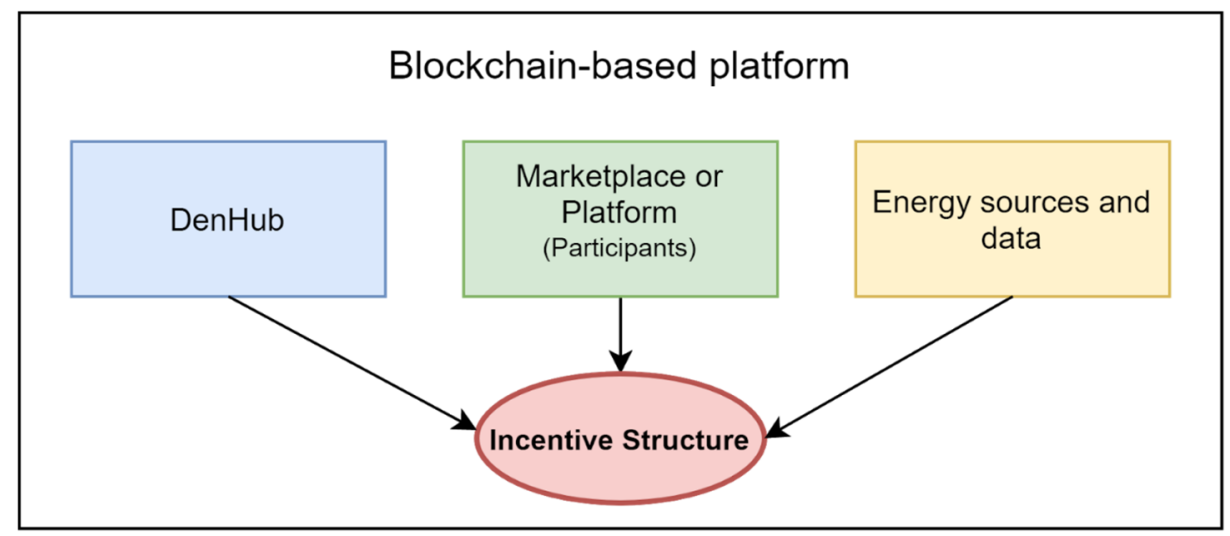

Figure 4. Incentive Structure of the Blockchain.

One of the main impediments to implementing decentralised blockchain applications is the complexity, required time, and energy cost of the mining algorithm used. The Blockchain's consensus algorithm determines this. However, the consensus algorithm used for Bitcoin, Proof of Work, has given way to more efficient algorithms such as Proof of Stake, which significantly reduces energy expenditure in mining transactions. With reduced complexity, not only energy expenditure decreases but also transaction durations as listed below, which is essential in terms of scalability:

- $\quad$ Bitcoin and Ethereum Blockchain (Proof of Work): approx. 15 transactions per second.

- Ethereum 2.0 Blockchain (Proof of Stake): approx. 100,000 transactions per second.

\subsection{Blockchain Typology}

\subsubsection{Public Systems}

Blockchain is considered public if all parties can read it and use it to conduct transactions and if anyone can engage in the process of reaching consensus. Anyone from anywhere can participate in such a system, and there are no limits on when users can enter or leave. There is no central registry or trusted third party. Scalability issues have arisen due to the characteristics of public blockchain systems. They also find it challenging to regulate sharing of information and visibility and comply with privacy regulations such as GDPR.

\subsubsection{Private Systems}

When using a private blockchain system in a specific blockchain network, unlike with a public blockchain system, only those who have been explicitly authorised by the present members or administrators of that network are allowed to be a part of that network. An organisation grants write access, and read permissions can be public or restricted. The user's identity is known and validated in this more restricted and controlled application of technology. Private blockchains are easier to design in a compliant way with data protection law than public networks.

Figure 5 depicts a blockchain typology segmented by the permission model. The permission impacts read, write, and in particular, commit authorisation. 


\begin{tabular}{|c|c|c|c|c|c|c|}
\hline & & & Read & Write & Commit & Example \\
\hline \multirow{4}{*}{ 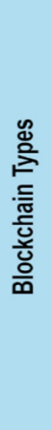 } & \multirow{2}{*}{$\frac{\text { 능 }}{2}$} & $\begin{array}{c}\text { Public } \\
\text { permissionless }\end{array}$ & Open to anyone & Anyone & Anyone & Bitcoin, Etherum \\
\hline & & $\begin{array}{c}\text { Public } \\
\text { permissionled }\end{array}$ & Open to anyone & $\begin{array}{l}\text { Authorised } \\
\text { participants }\end{array}$ & $\begin{array}{l}\text { All or subset } \\
\text { of authorised } \\
\text { participants }\end{array}$ & $\begin{array}{c}\text { Hyperledger } \\
\text { Fabric, R3 Corda }\end{array}$ \\
\hline & \multirow{2}{*}{ 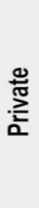 } & Consortium & $\begin{array}{l}\text { Restricted to an } \\
\text { authorised set of } \\
\text { participants }\end{array}$ & $\begin{array}{l}\text { Authorised } \\
\text { participants }\end{array}$ & $\begin{array}{l}\text { All or subset } \\
\text { of authorised } \\
\text { participants }\end{array}$ & $\begin{array}{c}\text { Multiple banks } \\
\text { operating a shared } \\
\text { ledger }\end{array}$ \\
\hline & & $\begin{array}{c}\text { Enterprise } \\
\text { (Private } \\
\text { permissioned) }\end{array}$ & $\begin{array}{c}\text { Fully private or } \\
\text { restricted to a limited } \\
\text { set of authorised } \\
\text { nodes }\end{array}$ & $\begin{array}{l}\text { Network } \\
\text { operator } \\
\text { only }\end{array}$ & $\begin{array}{l}\text { Network } \\
\text { operator } \\
\text { only }\end{array}$ & $\begin{array}{c}\text { Internal bank ledger } \\
\text { between } \\
\text { parent company } \\
\text { and subsidiaries }\end{array}$ \\
\hline
\end{tabular}

Figure 5. Blockchain Types.

\section{Results}

In DenHub, a model in which users and participants are segmented is preferred for a more scalable and effective system. Layer 1 includes the user part, while Layer 2 includes the consortium participants in the double layer hybrid system. Layer structure and hybrid model are depicted with examples in Figure 6.

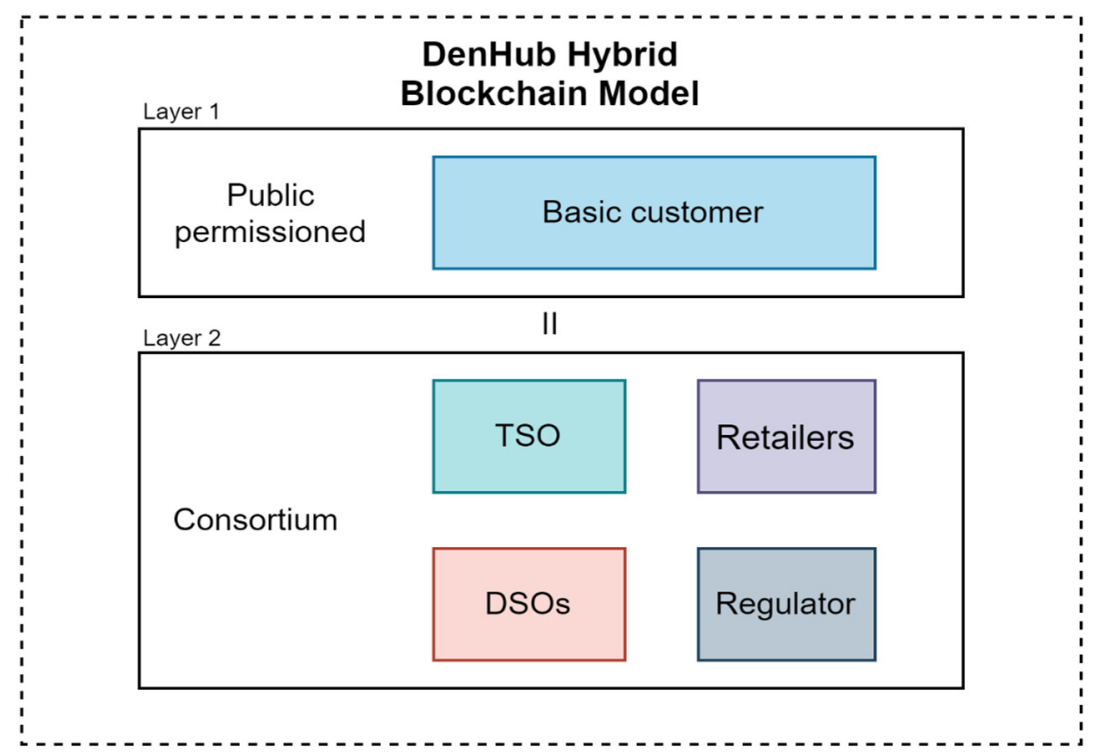

Figure 6. The DenHub Hybrid Blockchain Model

\subsection{Decentralised Storage and Cloud}

Storage of the collected vast amount of data is a concern for the planners. We investigate decentralised storage and cloud as convenient data storage media for a decentralised system.

\subsubsection{Cloud Storage Networks}

A cloud system is a multi-device, multi-application domain, and multi-service form storage service system provided by a single service provider. Cloud storage is less expensive, more dependable, and less prone to data loss than local storage [33]. Broadband networks, Web 2.0, database virtualisation, storage networks, application storage integrated with servers and storage devices, cluster technology, grid computing, distributed file system, content delivery network, peer-to-peer, data compression, data encryption, and other factors have all aided cloud storage systems' advancement. Cloud storage comprises hundreds of storage devices clustered together by network and other storage middleware 
to give customers cloud storage. Thousands of storage devices are linked together by a network, distributed file systems, and other storage middleware to form a cloud. Cloud storage services include Apple iCloud, Google Drive, and Dropbox.

\subsubsection{Decentralised Storage Networks}

Decentralised storage in the file system and database communities and data distribution for efficiency, reliability, and resilience have been extensively studied. Ficus and Coda are two systems that duplicate files for high availability at the cost of consistency. Farsite is a distributed file system that operates without the use of a central server. Cassandra is a distributed storage system that allows you to manage very large volumes of organised data across several commodity servers. One of the most important problems in such systems is the conflict between data. The mechanisms for resolving conflicts differ between these systems and define the characteristics of these systems.

\subsubsection{Blockchain-Based Decentralised Storage Systems}

Distributed or decentralised file storage systems do not require a trusted central authority overseeing and running the network when built on Blockchain. The concept of decentralised storage was pioneered in 2013-2015 by projects such as the IPFS (InterPlanetary File System), Storj, and Siacoin. The key idea behind the concept is to take advantage of the benefits associated with decentralised networks to improve the privacy, security, censorship resistance, cost, and affordability of file storage systems. Storj makes use of the Ethereum blockchain and maintains metadata in a Satoshi-style format, allowing users to access their data in its entirety whenever they need it. On the Storj platform, an application named Metadisk checks the network regularly to guarantee that the files saved are accessible and unaltered. The consensus process used in Storj is Proof of Space (PoS), also known as Proof of Storage or Proof of Capacity $(\mathrm{PoC})$. Each miner's network effect is directly proportional to the amount of dedicated free space [34]. Another blockchain-based storage platform is Sia [35]. Peers in Sia, like Storj, rent out their hardware capacity. In this network, storage providers are referred to as hosts. Storage proofs are publicly available and verified and include a list of hashes from the file as well as a small portion of the original file. FileCoin is built on IPFS and provides yet another decentralised storage network. To mitigate a single point of failure in the network, IPFS was created to connect all computing devices in a decentralised file system [36].

\subsection{The DenHub Model and Comparisons}

The systems that have been built so far have been evaluated, and their strengths and limitations identified. The DenHub model was developed by making requisite changes. Table 4 shows the comparisons and the DenHub model.

Table 4. The DenHub Storage Comparison.

\begin{tabular}{cccccccc}
\hline Storage Type & Blockchain & Decentralised & Open Source & Scalability & Privacy & $\begin{array}{c}\text { Data } \\
\text { Processing }\end{array}$ \\
\hline Cloud Storage Networks & No & No & No & High & Low & Yes \\
\hline Decentralised Storage Networks & No & Yes & No & Complicated & High & No \\
\hline Blockchain-based Storage Systems & Yes & Yes & Yes & Complicated & High & No \\
\hline DenHub & Yes & Yes & Yes & Complicated & High & Yes \\
\hline
\end{tabular}

\subsection{GDPR and Date Security}

\subsubsection{Smart Meters}

Energy consumption monitoring can assist enhance the quality and safety of electricity distribution, in the meantime allowing to draw conclusions regarding energy user activity if the person has access to the data. In 2012, both the European Data Protection Supervisor 
(EDPS) and the former Article 29 Working Party of Data Protection Supervisory Authorities determined certain threats to personal data security that were previously unknown to the energy sector [37].

Smart meters must comply with the EU's data protection laws, according to the EU's 2019 rules for the internal market for electricity and amending Directive [38]. The permission to collect data with these devices is according to Art. 6 Para. 1 lit. f. GDPR. After that, only those data may be collected that is necessary to prepare the respective statement. For example, newer wireless metres can theoretically collect more data than is required for (annual) billing planning. It is critical to note that additional data collection according to Art. 7 GDPR is allowed only with the express and written consent of the individuals concerned.

\subsubsection{Blockchain}

There is currently a lack of legal clarity about applying various European data protection legislation provisions to the Blockchain. The GDPR is a form of policy focused on broad principles. This provides versatility and adaptability benefits in an age of rapid technological change has drawbacks, such as finding it difficult to decide with certainty how a technical provision should be implemented in a particular context at times [39].

In such instances, regulatory guidance, certification mechanisms, and codes of conduct may not go far enough to resolve a lack of compliance. An interdisciplinary study addressing these issues could alleviate these technical and governance limitations.

\section{Discussion}

According to the International Energy Agency, about 10\% of the air quality, energy, geospatial data, asset and intervention databases, and traffic control systems data collected from IoT devices are being used as of 2021 [6]. We do not know the exact amount of energy data collected, processed, and put to use; however, we can estimate this amount should be negligible. On the other hand, World Economic Forum estimated that by 2027, around $10 \%$ of the global gross domestic product would be stored on Blockchain [40]. We do not have a solid estimate regarding the energy sector. However, the number of Blockchain applications in this sector is booming [32].

To overcome some of the regulatory uncertainties in this context, the European Union may facilitate the initiation of related procedures complementary to the provision of regulatory guidance. Technical and governance constraints, particularly those associated with blockchain technology, might be solved through an interdisciplinary study on these topics. As a result, governments and related regulators should encourage and support institutions representing diverse disciplines interested in this technology. Studies limited to one field, for example, engineering only, will not accurately reflect the whole picture.

Decentralised storage studies are at a much earlier stage than traditional cloud storage. As a result, it has certain drawbacks. However, it is constantly updated, and its shortcomings are addressed. Due to technological limits, blockchain-based IoT devices cannot provide a viable option. However, the newly built Blockchain systems have resolved these concerns with the transaction speed requirements. Many participants may wish to rent their storage space by joining the system from the outside, where they can be called trust nodes. These participants may gain certain benefits in return. However, this technology is still in its immaturity and faces several obstacles. Achieving a genuinely decentralised storage system's security, scalability, and cost-efficiency will require software of immense technical complexity.

The GSMA forecasts that $5 \mathrm{G}$ connections would increase from 10 million at the end of 2019 to 1.8 billion by 2025. 5G connectivity has the potential to be quicker, more stable, and more secure than current technologies. These characteristics can elevate it to a priority for IoT applications ranging from self-driving automobiles to smart grids for renewable energy. Also, traditional cloud systems can incorporate the benefits of decentralised systems into 
their architectures. Security, privacy, speed, and economic considerations will prioritise these solutions.

Energy Datahubs are quite novel concepts and centralised ones are only in operation in a few countries such as Denmark, Finland and Estonia. Unfortunately, we do not have a sufficient amount of data to support our model, as the data are either not produced nor publicly available yet. To make sure about the advantages and potential improvements in the Datahub ecosystem, information regarding how much of the data types such as fast detection and locating the anomalies in the power system, real-time pricing or other smart tariff service, Demand Response (DR) measures, algorithmic trading, or automated trading are used, manipulated and then converted into business/economic value should be shared by the companies that are listed in Table 1. We hope this paper will pave way to trial the DenHub model, or some other generic decentralised energy Datahub model by the industry in the near future. As a novel and unique contribution, the decentralised energy Datahub concept is proposed with this paper.

\section{Conclusions and Impact}

Continuous increase in energy demand, especially in developing economies, has motivated the energy industry to review their policies, answers, and moves against the irrepressible growth in energy demand where sustainability, security of supply, and affordability are the main concerns. The energy sector has been reforming towards a sustainable, secure, and affordable future. According to these goals, main activities are gathered around five, perhaps four and a half, trends (5D): Digitalisation, Decentralisation, Democratisation, Decarbonisation, and Deregulation. The DenHub is planning to bring a disruptive and sustainable solution to the energy sector by seeking these 5D goals.

Digitalisation is the key concept and enabler for the remaining 4Ds in the energy sector. It paves the way for businesses and new start-ups to build connected, efficient and reliable systems, which will help to organise a more efficient allocation of resources and to create a more sustainable environment on energy. The Denhub Model has become possible with the ongoing digitalisation of the energy sector over the decades. The disintermediation provided by Blockchain is changing the democratisation and facilitating access to financial instruments. At the same time, unlike a centralised structure, the operator nodes of the system can present a more democratic application in management.

The DenHub system will benefit, albeit indirectly, in Decarbonisation, which aligns with the United Nations Sustainable Development Goals. It will be essential in providing decarbonisation when the end-users are included by smart meters in the system and see their consumption through distributed ledger systems. Energy data will become accessible to users and participants. Including new users and participants in the system with various incentive mechanisms increases decentralisation. Data generated from distributed users create more inclusive and innovative new business models or reveal local energy solutions. With the decentralised control and management of data, the need for central regulations to avoid manipulation will be reduced, and hence a degree of deregulation might be achieved. With the new DenHub model, existing structural confusion between users and participants is reduced. The blockchain system makes relationships more transparent. Smart contracts formalise and secure relationships over energy networks. It will also pave the way to deregulation by eliminating intermediaries in energy data governance. We called the 5D trends 'perhaps four and a half' because deregulation is the most challenging path among other Ds. Even though there is a desire to decrease the regulations and the red tape, which is sometimes called 'excessive, rigid or redundant' by some market participants, the number of regulations increases day by day, especially in the European Union. Furthermore, we might argue that the excessive central regulations might contribute to central energy markets rather than decentralised ones. In any case, we believe that the DenHub model will be a crucial player in supporting digitalisation, decentralisation, democratisation, decarbonisation, and deregulation in the energy sector. 
One of the outputs of this model is the easy access to transparent and flexible data and the formation of new business models that will emerge upon the use of the data. The data produced, distributed, used, and curated will help researchers and entrepreneurs study this field and propose new business models to make the energy ecosystem more efficient, clean and inclusive.

Author Contributions: Conceptualization, S.K.; methodology and validation, S.K., E.A., Y.E.T. and T.Y.A.; writing —original draft preparation, E.A., Y.E.T. and T.Y.A.; writing—review and editing, J.P. and A.P. All authors have read and agreed to the published version of the manuscript.

Funding: This research received no external funding.

Institutional Review Board Statement: Not applicable.

Informed Consent Statement: Not applicable.

Data Availability Statement: Not applicable.

Conflicts of Interest: The authors declare no conflict of interest.

\section{References}

1. Wells, D. Data Hubs-What's Next in Data Architecture? 2019. Available online: https://www.eckerson.com/articles/datahubs-what-s-next-in-data-architecture (accessed on 15 July 2021).

2. Ernst \& Young. Energy Datahub Stakeholder Insights, Brisbane; Ernst \& Young: Sydney, Australia, 2018.

3. Küfeoğlu, S.; Üçler, Ş. Designing the business model of an energy Datahub. Electr. J. 2021, 34, 106907. [CrossRef]

4. Western Power. Energy Data Hub. 2021. Available online: https://www.westernpower.co.uk/our-network/energy-data-hub (accessed on 15 July 2021).

5. Fingrid. What Is Datahub? 2021. Available online: https://www.fingrid.fi/en/electricity-market/datahub (accessed on 15 July 2021).

6. International Energy Agency. Empowering Cities for a Net Zero Future: Unlocking Resilient, Smart, Sustainable Urban Energy Systems; IEA: Paris, France, 2021.

7. Alahakoon, D.; Yu, X. Smart Electricity Meter Data Intelligence for Future Energy Systems: A Survey. IEEE Trans. Ind. Inform. 2016, 12, 425-436. [CrossRef]

8. Cabral, J.E.; Pinto, J.O.P.; Martins, E.M.; Pinto, A.M.A.C. Fraud detection in high voltage electricity consumers using data mining. In Proceedings of the 2008 IEEE/PES Transmission and Distribution Conference and Exposition, Chicago, IL, USA, 21-24 April 2008; pp. 1-5. [CrossRef]

9. Gareta, R.; Romeo, L.M.; Gil, A. Forecasting of electricity prices with neural networks. Energy Convers. Manag. 2006, 47, 1770-1778. [CrossRef]

10. Company, D.C. DCC Web Page. 2020. Available online: https://www.smartdcc.co.uk/ (accessed on 12 May 2020).

11. Lund, H.; Østergaard, P.A.; Connolly, D.; Mathiesen, B.V. Smart energy and smart energy systems. Energy 2017, 137, 556-565. [CrossRef]

12. O'connell, N.; Pinson, P.; Madsen, H.; O'malley, M. Benefits and challenges of electrical demand response: A critical review. Renew. Sustain. Energy Rev. 2014, 39, 686-699. [CrossRef]

13. Perera, A.; Nik, V.M.; Wickramasinghe, P.; Scartezzini, J.-L. Redefining energy system flexibility for distributed energy system design. Appl. Energy 2019, 253, 113572. [CrossRef]

14. European Forum for Energy Business Information. Survey: Datahub. 2019. Available online: https:/ / mwgstorage1.blob.core. windows.net/public/Ebix/EBG\%20Survey\%20DataHub\%20v1r1\%2020190607\%20(1).pdf (accessed on 8 June 2020).

15. Sovacool, B.K.; Del Rio, D.F. Smart home technologies in Europe: A critical review of concepts, benefits, risks and policies. Renew. Sustain. Energy Rev. 2019, 120, 109663. [CrossRef]

16. ebIX Business Group. Survey: DataHub, s.l.: European Forum for Energy Business Information eXchange. 2019. Available online: https:/ / mwgstorage1.blob.core.windows.net/public/Ebix/EBG\%20Survey\%20DataHub\%20v1r0\%2020190328.pdf (accessed on 15 July 2021).

17. Pidun, U.; Reeves, M.; Schüssler, M. How Do You “Design” a Business Ecosystem? 2020. Available online: https:/ /www.bcg. com/publications/2020/how-do-you-design-a-business-ecosystem (accessed on 16 August 2021).

18. Conejo, A.; Sioshansi, R. Rethinking restructured electricity market design: Lessons learned and future needs. Int. J. Electr. Power Energy Syst. 2018, 98, 520-530. [CrossRef]

19. De Vries, A. Bitcoin's growing energy problem. Joule 2018, 2, 801-805. [CrossRef]

20. Küfeoglu, S.; Liu, G.; Anaya, K.; Pollitt, M. Digitalisation and New Business Models in Energy Sector; Faculty of Economics, University of Cambridge: Cambridge, UK, 2019.

21. Le, T.N.; Chin, W.L.; Truong, D.K. Advanced Metering Infrastructure Based on Smart Meters in Smart Grid. In Smart Metering Technology and Services-Inspirations for Energy Utilities; Elsevier: Amsterdam, The Netherlands, 2016. 
22. European Commission DG Energy. European Smart Metering Benchmark, Brugge: S.n. 2019. Available online: https://www. vert.lt/SiteAssets/teises-aktai/EU28\%20Smart\%20Metering\%20Benchmark\%20Revised\%20Final\%20Report.pdf (accessed on 15 July 2021).

23. Department for Business, Energy \& Industrial Strategy (BEIS). Smart Meter Statistics in Great Britain: Quarterly Report to End December 2020, London; Department for Business, Energy \& Industrial Strategy: London, UK, 2021.

24. Statista. Number of Households in the US 1960-2020; Statista Research Department: New York, NY, USA, 2021.

25. US Energy Information Administration. How Many Smart Meters Are Installed in the United States, and Who Has Them? 2020. Available online: https: / / www.eia.gov / tools / faqs / faq.php?id=108\&t=3 (accessed on 16 July 2021).

26. Simon, F. Smart Meter Woes Hold Back Digitalisation of EU Power Sector. 2019. Available online: https://www.euractiv.com/ section/energy/news/smart-meter-woes-hold-back-digitalisation-of-eu-power-sector/ (accessed on 16 July 2021).

27. Gerpott, T.J.; Paukert, M. Determinants of willingness to pay for smart meters: An empirical analysis of household customers in Germany. Energy Policy 2013, 61, 483-495. [CrossRef]

28. Uribe-Pérez, N.; Hernández, L.; De la Vega, D.; Angulo, I. State of the Art and Trends Review of Smart Metering in Electricity Grids. Appl. Sci. 2016, 6, 68-92. [CrossRef]

29. Lipošćak, Z.; Bošković, M. Survey of Smart Metering Communication Technologies. Eurocon 2013, 2013, 1391-1400.

30. Androutsellis-Theotokis, S.; Spinellis, D. A survey of peer-to-peer content distribution technologies. ACM Comput. Surv. 2004, 36, 335-371. [CrossRef]

31. Beck, R.; Stenum, J.; Lollike, N.; Malone, S. Blockchain-The Gateway to Trust-Free Cryptographic Transactions. Istanbul, s.n. 2016. Available online: https://pure.itu.dk/portal/en/publications/blockchain--the-gateway-to-trustfree-cryptographictransactions(c0965a66-038d-456f-b1c2-bb32282bd28a).html (accessed on 15 July 2021).

32. Küfeoğlu, S.; Özkuran, M. Bitcoin mining: A global review of energy and power demand. In Energy Research E Social Science; Elsevier: Amsterdam, The Netherlands, 2019.

33. Zeng, F.; Hu, Z.; Chen, R.; Yang, Z. Determinants of online service satisfaction and their impacts on behavioural intentions. Total Qual. Manag. 2009, 20, 953-969. [CrossRef]

34. Mahmood, A.W. Survey of Consensus Protocols. 2020. Available online: https://papers.ssrn.com/sol3/papers.cfm?abstract_id= 3556482 (accessed on 16 July 2021).

35. David, V.; Champine, L. Sia: Simple Decentralised Storage; Nebulous Inc.: Boston, MA, USA, 2014. Available online: https: / / sia.tech/sia.pdf (accessed on 15 July 2021).

36. Benet, J. IPFS - Content Addressed, Versioned, P2P File System. arXiv 2018, arXiv:1407.3561.

37. Riemann, R. TechDispatch \#2: Smart Meters in Smart Homes. 2019. Available online: https://edps.europa.eu/data-protection/ our-work/publications/techdispatch/techdispatch-2-smart-meters-smart-homes_en (accessed on 16 July 2021).

38. European Parliament EUR-Lex-32019L0944-EN_EUR-Lex. Available online: https://eur-lex.europa.eu/eli/dir/2019/944/oj (accessed on 16 July 2020).

39. Finck, M. Blockchain and the General Data Protection Regulation-Can Distributed Ledgers Be Squared with European Data Protection Law; European Parliamentary Research Service: Brussels, Belgium, 2019. Available online: https://www.europarl.europa.eu/ RegData/etudes/STUD/2019/634445/EPRS_STU(2019)634445_EN.pdf (accessed on 15 July 2021).

40. World Economic Forum. Global Agenda Council on the Future of Software \& Society. Deep Shift Technology Tipping Points and Societal Impact, Survey Report. 2015. Available online: http:/ /www3.weforum.org/docs/WEF_GAC15_Technological_Tipping_ Points_report_2015.pdf (accessed on 20 June 2019). 